\title{
A NOVEL MEDIUM FOR MOUNTING NEMATODES
}

The writer has found that Hoyer's modification of the Berlese solution ${ }^{1}$ makes an excellent mounting medium for nematodes. The formula of this medium is as follows:

$50 \mathrm{gm}$. distilled water

$30 \mathrm{gm}$. gum arabic (clear crystals)

$200 \mathrm{gm}$. chloral hydrate

20 gm. glycerin

The ingredients are mixed in the above order at room temperature. It should be noted that the gum arabic used is pure elear erystal which will go rapidly into solution; if the powdered gum arabic is used, great difficulty is generally encountered in dissolving it. After the slides are ready they should be heated in an oven at $40^{\circ} \mathrm{C}$, , in ordel to set them. In humid areas it is best to ring cover glasses to prevent absorption of moisture.

This technique of mounting has been used with animal and plant nematodes. Animal nematodes were collected from dead rabbits preserved in formalin as well as from living animals, and placed directly into the mounting medium. The same procedure was used with plant material which also had been preserved in formalin.

${ }^{1}$ Baker, E. W. and Wharton, G. W., An Introduction to Acarology MacMillan Co., New York, N. Y., p. 10.

The advantages of this melium are: (1) The direct mounting of living or dead material from an acpueous solution. (2) The possibility of remounting easily if the medium fails to loring out rertain morphologieal characters. This should be done by placing the slide in hot water which would aid in slipping off the cover slip. On oceasion, I have found out that the pharyngeal characters will sometimes be obseure in this medium. In this case iodine crystals added to the medium will be of great help. (3) The slides mounted in this medium ean be examined almost immediately. (t) The cuticular structures of nematodes are rery distinet when this medium is used. 